\title{
THE DESIGN OF WEB-BASED INFORMATION SYSTEM OF BATIK INDONESIA
}

\author{
Agus Hamdi \\ Information Systems Department, School of Information Systems, Bina Nusantara University \\ Jl. KH. Syahdan No. 9, Jakarta 11480, Indonesia. \\ agushamdi@yahoo.co.id
}

\begin{abstract}
While the Government is heavily promoting batik abroad, it turned out the conditions within the country is not much supportive. Many of the younger generation are not interested in acquiring the art of batik since batik artisans are still largely dominated by the old. Not to mention the problem of the patent of a few motifs that turns out to have been intercepted by Malaysia. Seeing the dark future of this batik, it needs an effort to preserve the traditional batik by not to be drown in the flood of modern life that lacks of appreciation of traditional batik. In anticipating of that, Indonesian batik needs web information that supports and provides satisfactory service for the visitors of the website.
\end{abstract}

Keywords: Batik Information, website

\section{INTRODUCTION}

Nowadays, culture change has become the result of worldwide Internet utilization. Therefore, rapid technology development has to be responded by utilizing the technology in obtaining information. Internet is one of a container of the latest technology, which can be used as a media in spreading information of Batik Indonesia to many people in all around the world, particularly to internet users. Moreover, the website visitors can obtain information about the products of Batik Indonesia that they want regarding multiple types of batik and its history.

A good information system is expected to meet the criteria, which are effective, efficient, fast, and accuracy in term of either energy or time, so it will produce information, accessibility, reliability, and safety in applying the system. To increase and expand promotions about Batik Indonesia, it is the time for an information system to be designed and built that can serve the needs of information about Batik for all the internet users.

The goal of this research is to design a webbased information system about Batik Indonesia that can give information of Batik online about the histories and the types of Batik Indonesia, so it will help the speed and quality in conveying information. Moreover, information and data can be accessed in unspecified time and place.

\section{Internet}

According to Ref. [1], Internet is a collection of different networks that interconnected together as one of the unities with different network that interconnected together by using various protocol, one of them is TCP/IP (Transmission Control
Protocol/Internet Protocol). According to Ref. [2], Internet, which is known right now, was first developed in 1969 with the name of ARPAnet (US Defense Advanced Research Project Agency) by The United States Department of Defense. APRANET was built with the target to make a computer network wide-spread in order to avoid the centralization of information in one point which is considered as an easy target to be destroyed if there is a war. In early 80's, APRANET is divided into two networks, which are APRANET and Milnet (a military network), but both of them have connections so the communication between the fixed networks can be done. At first, this interconnection network was called DARPA Internet, but gradually be called Internet only.

According to Ref. [3], the facilities that are available in the Internet, include:

a. E-mail

E-mail is a type of service in the internet that is the most popular, which is an electronic letter service that can be used to send or answer messages, to send files as a part of e-mail news, and subscribes to the news to some discussion groups.

b. Mailing List

The use of e-mail can be developed to a MailingList service. This service is useful for subscribing to information from a discussion group being in demand or a discussion facility that is fun.

c. Internet Relay Chat (Chatting) This chatting service is a cheap facility for users who accessing to communicate in textual way. So, the users communicate through writing that is typed. Then, ther accessing user partner will reply in a form of writing too. 
d. USENET and Newsgroup

This type of service is Bulletin Board Service (BBS) in a form of message. Every internet users can join to exchange information to each other. Newsgroup is a long distance electronic conference facility for the internet users based on competency or certain area of interest.

e. File Transfer Protocol

Through this internet service, the users can also send files that contain writing, pictures, animation, music, or game to their partners. FTP allows the users to copy the files in electronic way from one computer to other computer in the internet.

f. Telnet

Telnet is a facility which is as if directly connecting the computer of the user with the partner via internet.

g. Web Browser

To access internet, an application program is needed, which is called Web Browser. This application program has the ability to show a web page that is written in HTML format.

h. Word Wide Web

Multimedia internet service or known as World Wide Web (WWW) is an internet application that is enthused by the internet user. WWW is loved because it covers multimedia resources, include voices, picturesm videos, audio, and animation. Therefore, the application becomes a facility that provides interactive, and attractive information. WWW service is more known as web.

\section{Adobe Dreamweaver CS5}

According to Ref. [4], Adobe Dreamweaver CS5 is the most popular web-editor application program today. Dreamweaver provides an editing HTML facility visually. This application includes various facilities and web-program technology like HTML, CSS, and Javascript. Besides that, this application also allows the editing of Javascript, XML, and other text documents directly. This application also supports the programming of Script Server Side such as PHP, Active Server Page (ASP), ASP.NET, ASP Javascript, ASP VBScript, ColdFusion, and Java Server Page (JSP).

\section{Personal Home Pages (PHP)}

According to Ref. [5], PHP is the shortened of PHP Hypertext Preprocessor. It is a language in a form of script that is placed in a server and processed in a server. The result that is sent to the client, the place where the users uses browser. Specifically, PHP is designed to form a dynamic web application. It means, it can form a performance based on the latest demand. For example, the content of database can be shown to the web page. In principle, PHP has functions that is similar with scripts such as ASP
(Active Server Page, Cold Fusion, or Perl. But, it is needed to be known that PHP actually can be used in by command line. It means that PHP script can be conducted without involving the web server or the browser. The birth of PHP started when Rasmus Lerdorf made a number of Perl scripts that can observe anyone who were looking up to the list of his memoir, which was in 1994. These scripts next are packed into tool, which is called Personal Home Page. These packages that becomes the forerunner of PHP.in 1995, Rasmus created PHP/FI version 2.

In this version, the programming can attach structured codes in the HTML tag. Interestingly, PHP code also can communicate with database and cam do complicated calculations while running. Right now, PHP is quite popular as web-programming device, especially in the environment of Linux. Nebertheless, PHP actually can function in some servers, which are based on UNIX, Windows, and Macintosh. At first, PHP is designed to be integrated with web server Apache. But, lately PHP can also work with web server like PWS (Personal Web Server), IIS (Internet Information Server), and Xitami.

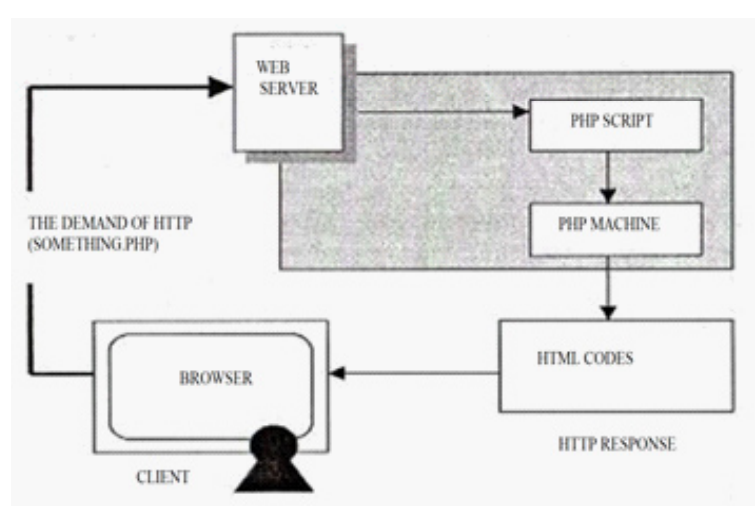

Fig. 1: The scheme of PHP

\section{MySQL (My Structured Query Language)}

According to Ref. [6], MySQL is a software, which is classified as DBMS (Database Management System), that is open source that can be downloaded by free in www.mysql.com. MySQL, at first, was made by the corporation of consultant named TcX that is located in Sweden. Right now, the development of MySQL is under a shade of the MySQL AB corporation. As DBMS softwarem MySQL has a number of features, as it is explained in the following: (1) Multiplatform: MySQL is available at some platforms (Windows, Linux, Unix and many else). (2) Reliably fast and easy to be used: MySQL is classified as a database server (a server that serves for serving database) that can handle a large database at high speed. It supports many functions to access database and also easy to be used. Some supporting tools is also available (although it is made by other 
party). It is needed to know that MySQL can handle a table that is measured in terabyte ( 1 terabyte $=1024$ gigabyte). But, the real size depends on the limitation of operation system. For example, in Solaris 9/10 system, the limitation of the file size is 16 terabyte. (3) A security guarantee access: MySQL supports the safety of database with various criteria of accessing. As a picture, it is enabled to set certain users so they can access the data that is secret, meanwhile other users cannot access it. (4) MySQL Support: As implicit in the name, MySQL supports SQL (Structured Query Language) command. As known, SQL is a standard in accessing relational database. The knowledge about SQL will ease anyone to use MySQL.

\section{Adobe Photoshop CS2}

According to Ref. [7] stated that Adobe Photoshop CS2 is the most popular and influencing graphic design software. It is launched in the middle of 2005, Adobe Photoshop CS2 offers new features and improvements from the previous version, which was Photoshop CS.

There are several things that can be done using this software: (1) Editing, repairing, and beautifying digital photos. (2) Designing graphic design, starts from cartoon, brochure, leaflet, and other printed goods. (3) Designing digital works for wallpaper, icon, and website with the help of Adobe ImageReady CS2. (4) Organizing, finding, and sharing digital photos by using Adobe Bridge.

\section{Navigation Structures}

According to Ref. [8] Navigation Structure is the arrangement of menu or hierarchy of a site that depicts the content of every pages and links, or the navigation of every pages in a website. A website navigation structure is highly influenced by the goal of the website that will be made. Navigation structure can be classified in accordance with the needs of objects, the ease of using, the interactivities, and the ease of making it that is influential to the time of a website-making.

\section{Linear (One way)}

Linear (one way) is a structure that only has one series of sequential stories. In the other word, this structure can only show one by one of screen displays in a sequence based on its order. The display that can be shown in this type of structure is one previous page or one after page and cannot show two previouspages or two after pages. One of the important things from this structure is branching is not allowed.

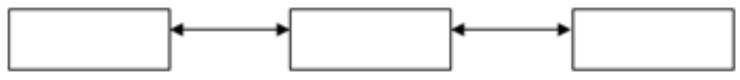

Fig. 2: Linear Navigation Structure

\section{Hierarchical}

This hierarchy structure (branch) is the branching to show data according to certain criteria. The display in the first menu will be called as Master Page (the first main page), this main page will have branching page that is stated as Slave Page (supporting page). If one of the supporting pages is chosen or activated, then the display will called the Master Page (the second main page), and so on. The most important thing from this trailing structure, linear display is not allowed.

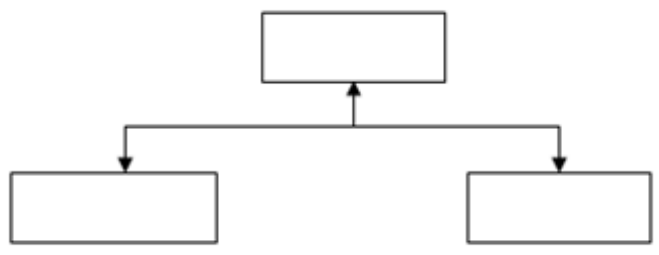

Fig. 3: Hierarchy Navigation Structure

\section{Non Linear (not in sequence)}

Non Linear trailing structure (not in sequence) is the development of Linear trailing structure. In this structure, it is allowed to make branched trailing. Users are free to browse the website without being limited by a route where the control of navigation can access to every pages. The branching that is made in this Non Linear structure is different with the branching in the Hierarchy structure, because in this Non Linear branching, even though there is branching, but every displays have same positions, there are no Master Page and Slave Page.

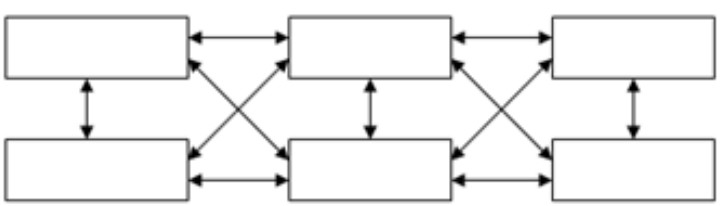

Fig. 4: Non Linear Navigation Structure

\section{Composite (Mixture)}

Composite (mixture) or also called free trailing structure is a combination of three previous structures, which are Linear, Non Linear, and Hierarchy. If a display needs branching, then branching can be made, and if in the branching there is a similar display, then Linear structure can be made in the branching.

Every map structures of trailing as previously discussed, have their own functions and goals, there is nothing better or worse. The use of trailing map depends on the needs and goals of the web that is going to be made. The more complex the trailing map that is used, then it is also more difficult the making of page from the trailing map. 


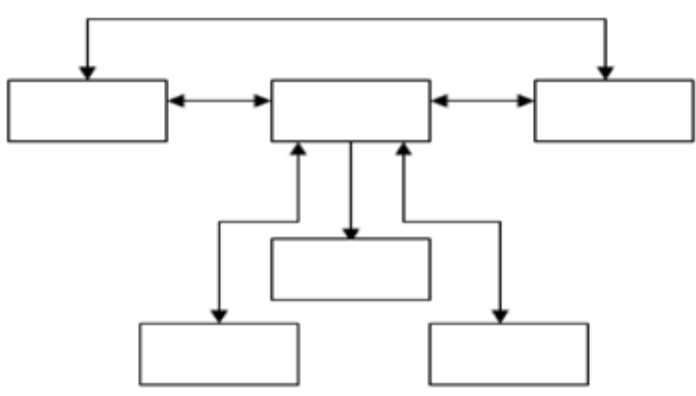

Fig. 5: Mixed Navigation Structure

\section{METHOD}

The method that is used in this research is the data collection method, which consists of literature study, field research that is conducted with observation, data collection, and interview, meanwhile the analysis method and the design of system is using the method of System Development Life Cycle (SDLC).

\section{RESULTS AND DISCUSSION}

\section{The Specification of Website Design}

In making the Information Website, Batik Indonesia has several stages of the design, which are: making the database, making table, designing the web display and managing to keep the file.

\section{The Design of Index Page (Home Page)}

Index is the front page of all of it in the website. This page also can be called as opening page because at the first time a website is opened, then this page will show up before any other pages. In the index page will be designed quite complex because there is links to every pages.

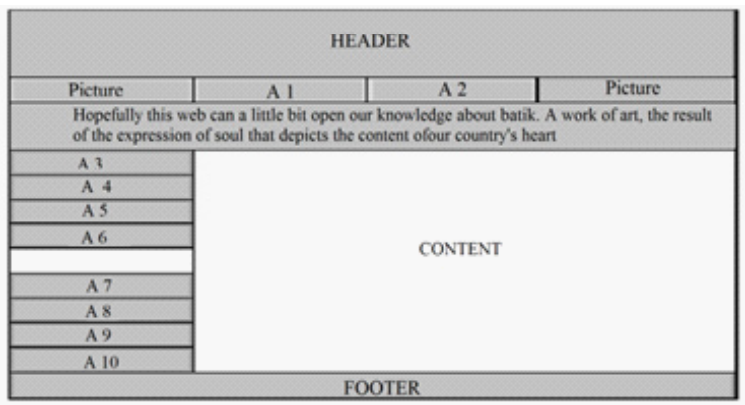

Fig. 6: The Design of Index Page

Descriptions:

A $1=$ The function of home page is to show home page menu.

A 2 = The function of guest book is to show the guest book menu.

A 3 = The function of history is to show the menu of the batik's histories in Cirebon, Jawa,
Keraton, Pekalongan, Solo, and Yogyakarta.

A $4=$ The function of About Us is to show the About Us menu.

A 5 = The function of Batik Types it to show the menu of batik stamp, print, and write types.

A $6=$ The function of Contact is to show the contact menu.

A7 $=$ The function of Facebook is to show the Facebook menu.

A $8=$ The function of Twitter is to show the Twitter menu.

A $9=$ The function of Google is to show the Google menu.

A $10=$ The function of Yahoo is to show the Yahoo menu.

\section{The Design of Login Page}

The Login page in this website is a special page that can be accessed by the administrator. To access the page, an admin is supposed to login by using certain password that is only known by the admin. After success to be accessed, in the inside will be shown the page of administrator.

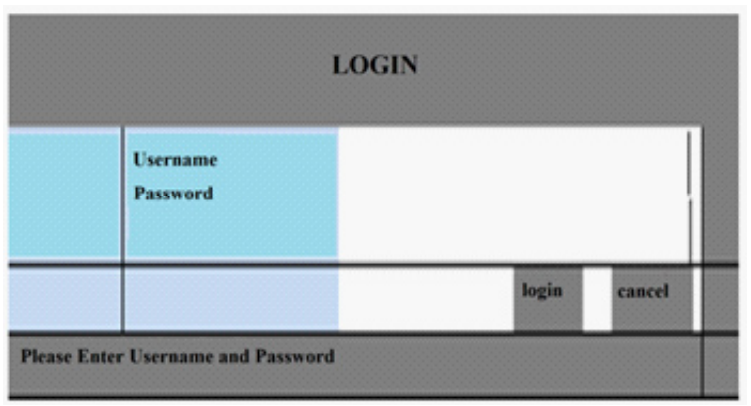

Fig. 7: The Design of Admin Page (Login)

\section{The Design of Administrator Page}

Administrator in this website is the next step after the process of login has succeeded. In the administrator, there is a number of menu to input, edit, and delete the data that every time can be used by an admin in accordance with the needs.

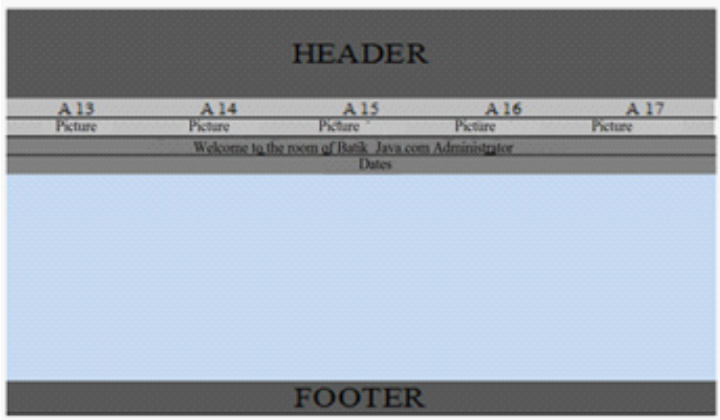

Fig. 8: The Design of Administrator Page 
Descriptions:

A13 = The function of Home is to show the home page menu,

A14 $=$ The function of Delete is to show the Delete menu of batik and guest book.

A15 $=$ The function of Input is to show the Input menu.

A16 $=$ The function of Edit is to show the Edit menu

A17 $=$ The function of Logout is to show the admin menu.

\section{The Design of Input Data Page}

Input Data in this website is a page that is used by an admin to eneter and to add data that is going to be shown in the website.

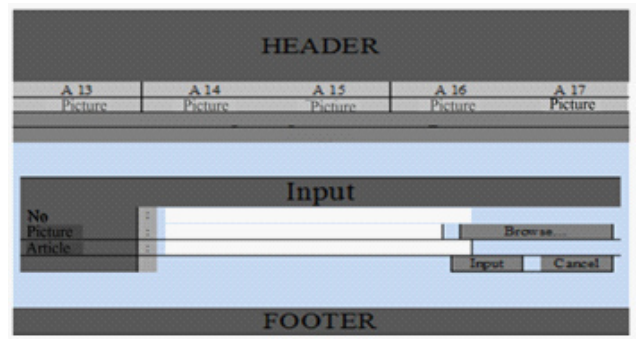

Fig. 9: The Design of Data Input Page

Descriptions:

A13 $=$ The function of Home is to show the home page menu,

A14 $=$ The function of Delete is to show the Delete menu of batik and guest book.

A15 $=$ The function of Input is to show the Input menu.

A16 $=$ The function of Edit is to show the Edit menu

A17 $=$ The function of Logout is to show the admin menu.

\section{The Design of Edit Data Page}

Edit Data in this website is the page that has facilities to change the available data according to the condition of data at that moment. As example, if there is the data of goods which its stock decreases, then an admin can change the stock with this facility.

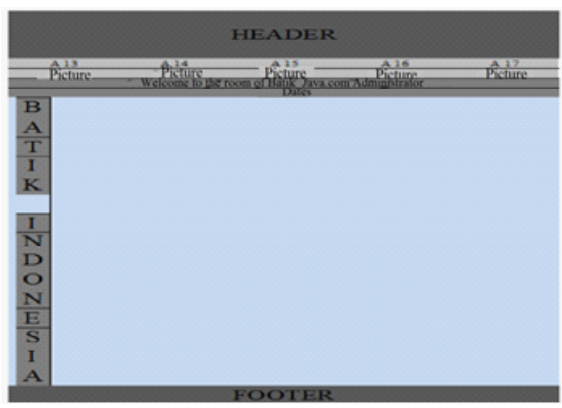

Fig. 10: The Design of Edit Data Page
Descriptions:

A13 $=$ The function of Home is to show the home page menu,

A14 $=$ The function of Delete is to show the Delete menu of batik and guest book.

A15 $=$ The function of Input is to show the Input menu.

A16 $=$ The function of Edit is to show the Edit menu

A17 $=$ The function of Logout is to show the admin menu.

\section{The Design of Delete Data Page}

Delete Data in this website is the page that has function to delete the available data based on the condition of data at that moment. For example, if batik or comments have overloaded, then an admin can erase the data.

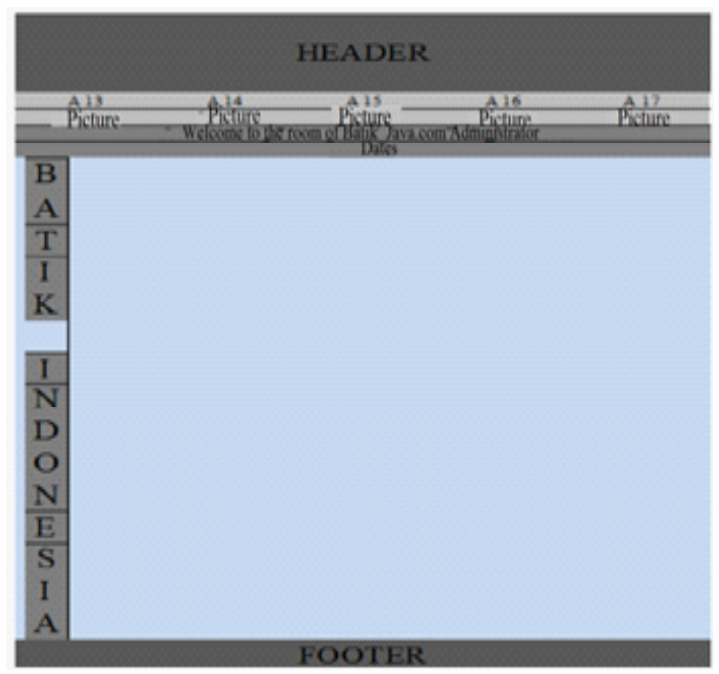

Fig.11: The Design of Delete Data Page

Descriptions:

A13 $=$ The function of Home is to show the home page menu,

A14 $=$ The function of Delete is to show the Delete menu of batik and guest book.

A15 $=$ The function of Input is to show the Input menu.

A16 $=$ The function of Edit is to show the Edit menu

A17 $=$ The function of Logout is to show the admin menu.

\section{The Design of About Us Page}

About Us in this website is the page that gives general information about the content of the website including the owner, which in this case is the website of Batik Indonesia information. 


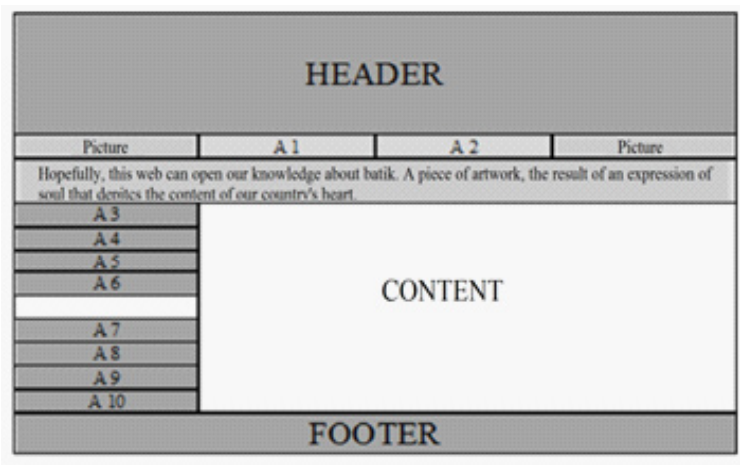

Fig. 12: The Design of About Us Page

Descriptions:

A $1=$ The function of home page is to show home page menu.

A 2 = The function of guest book is to show the guest book menu.

A 3 = The function of history is to show the menu of the batik's histories in Cirebon, Jawa, Keraton, Pekalongan, Solo, and Yogyakarta.

A $4=$ The function of About Us is to show the About Us menu.

A 5 = The function of Batik Types it to show the menu of batik stamp, print, and write types.

A $6=$ The function of Contact is to show the contact menu.

A7 $=$ The function of Facebook is to show the Facebook menu.

A $8=$ The function of Twitter is to show the Twitter menu.

A 9 = The function of Google is to show the Google menu.

A $10=$ The function of Yahoo is to show the Yahoo menu.

\section{The Design of Contact Page}

Contact in this website is the page that contains information about e-mail address, Facebook address, and Twitter address. This information is very useful for the visitors who will search for information that are related to batik Indonesia in this website.

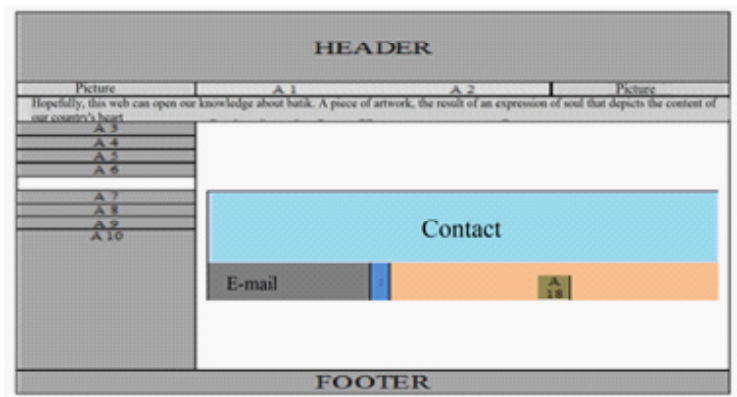

Fig. 13: The Design of Contact Page
Descriptions:

A $1=$ The function of home page is to show home page menu.

A 2 = The function of guest book is to show the guest book menu.

A 3 = The function of history is to show the menu of the batik's histories in Cirebon, Jawa, Keraton, Pekalongan, Solo, and Yogyakarta.

A $4=$ The function of About Us is to show the About Us menu.

A 5 = The function of Batik Types it to show the menu of batik stamp, print, and write types.

A $6=$ The function of Contact is to show the contact menu.

A7 $=$ The function of Facebook is to show the Facebook menu.

A $8=$ The function of Twitter is to show the Twitter menu.

A $9=$ The function of Google is to show the Google menu.

A10 $=$ The function of Yahoo is to show the Yahoo menu.

A18 $=$ The function of E-mail is to show e-mail menu.

\section{The Design of Guest Book Page}

Guest Book in this website is the page that has facilities to give easiness for the website visitors in seding a message or a comment.

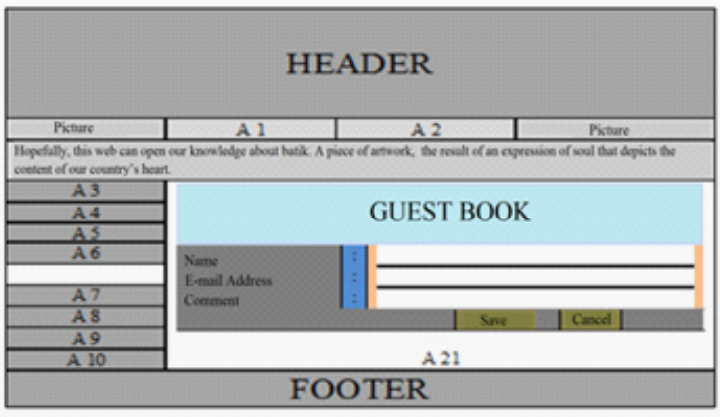

Fig. 14: Rancangan Halaman Buku Tamu

Descriptions:

A $1=$ The function of home page is to show home page menu.

A 2 = The function of guest book is to show the guest book menu.

A 3 = The function of history is to show the menu of the batik's histories in Cirebon, Jawa, Keraton, Pekalongan, Solo, and Yogyakarta.

A $4=$ The function of About Us is to show the About Us menu.

A 5 = The function of Batik Types it to show the menu of batik stamp, print, and write types.

A $6=$ The function of Contact is to show the contact menu. 
A7 $=$ The function of Facebook is to show the Facebook menu.

A 8 = The function of Twitter is to show the Twitter menu.

A 9 = The function of Google is to show the Google menu.

A10 $=$ The function of Yahoo is to show the Yahoo menu.

A21 $=$ The function of See Comments is to show the see comment menu.

\section{The Design of Navigation Structure}

Website Navigation Structure is used to describe in outline the content of all in the website, and describe how the relationship between the contents.
Determining navigation sturcture is a thing that is better be done before making the website. In this stage, it contains pictures of a web conceptually, and has a concept about what kind of information that will be determined to be shown in the website. The goals are so that the page, which is made, can be arranged well-organized also to be more clear, and facilitate in the specification information understanding in the pages that will be made. Navigation structure that is made in this website is a mixture navigation structure.

This navigation structure is needed to determine the flow of visualization from the beginning to the ending, where the main display contains the guidance and links that connect to the next page.

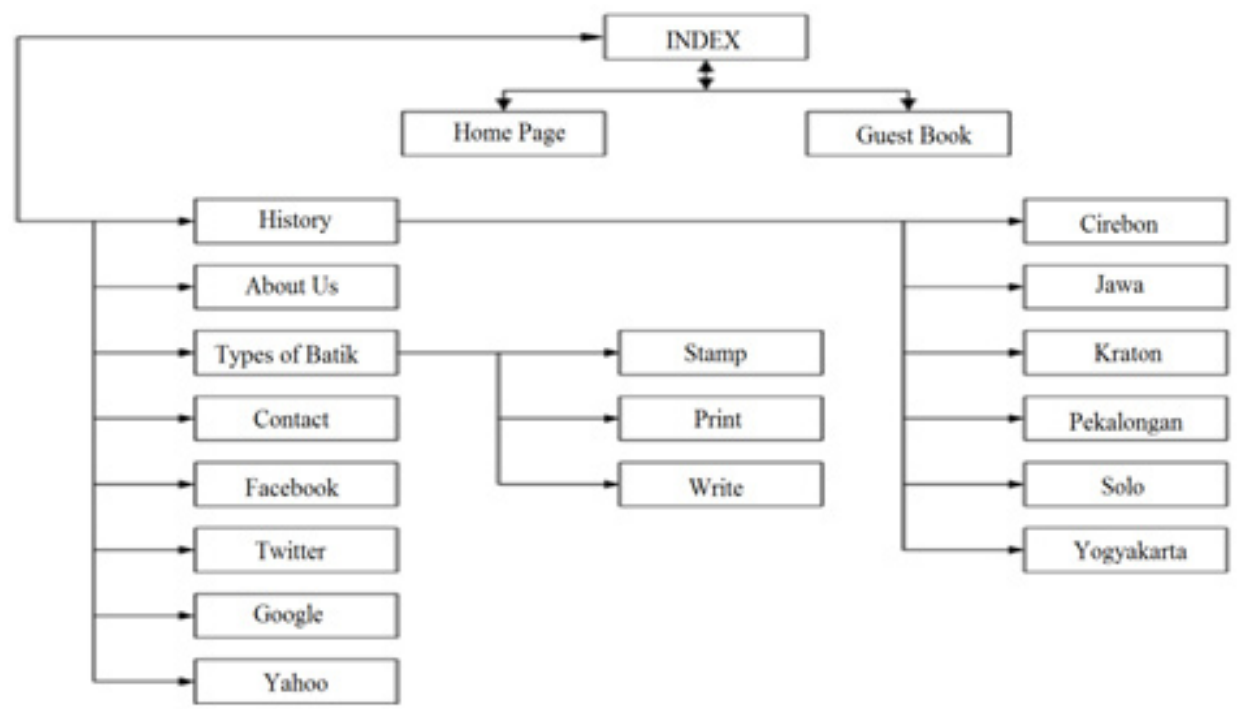

Fig. 15: The Main Menu of Mixture Navigation Structure

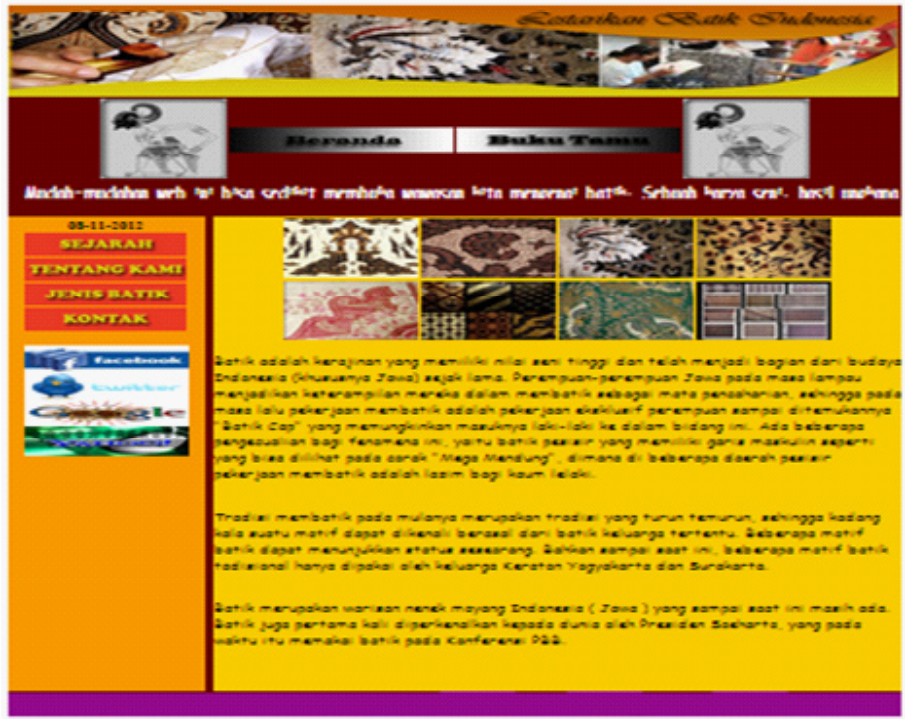

Fig. 16: The Result of Index Page 


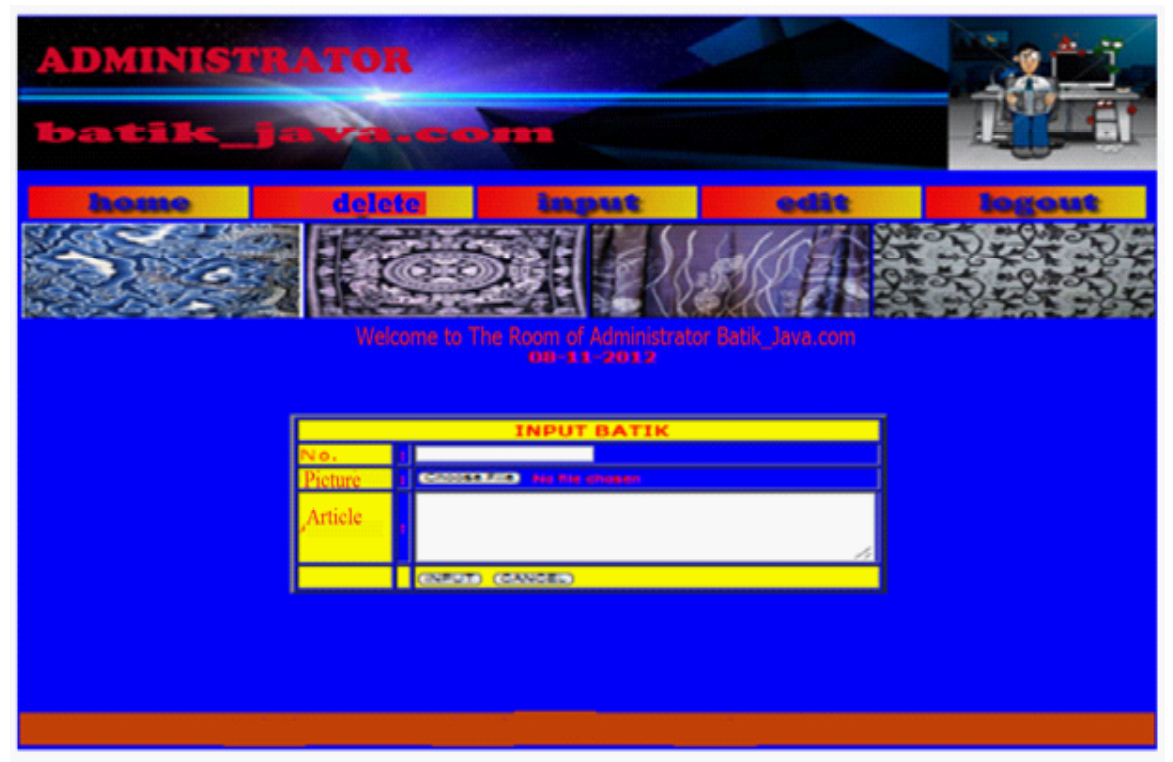

Fig. 17: The Result of Input Data Page

\section{CONCLUSION}

With internet, information can be gained quickly, correctly, and accurately. It also can be accessed by anyone without obstructed by geographical location as long as there is connection to the internet, so it is a very good delivery of information. Besides that, by using the facility of batik information website, the public can obtain information about the history of batik quickly and accurately, so that efficency and effectivity can be experienced by the public themeselves. One of the things that affects the visitors to visit a website is the attractive (eye catching) display, professional looks and useful content. Those will determine the image of the owner of the website.

\section{REFERENCES}

[1] G. Agung, Beginner's Guide Adobe Photoshop CS2, Jakarta: PT. Elex Media Komputindo, 2005.

[2] B. S. D. Oetomo, E. Wibowo, E. Hartono, S. Prakoso. Pengantar Teknologi Informasi Internet, Konsep dan Aplikasi. Yogyakarta: Andi, 2007.

[3] J. Febrian, Menggunakan Internet, Bandung: Informatika, 2008

[4] A. Kadir, Dasar Pemrograman Web Dinamis Menggunakan PHP (Revisi), Yogyakarta: Andi, 2008

[5] M. Shalahuddin, Rosa A.S, Java di Web, Bandung: Informatika, 2008

[6] B. Nugroho, Latihan Membuat Aplikasi Web PHP \&\& MySQL dengan Menggunakan MX $(6,7,2004)$ dan 8, Yogyakarta: Gava Media, 2008

[7] D. P. Oktavian, Menjadi Programer Jempolan Menggunakan PHP, Yogyakarta: Penerbit Mediakom, 2010

[8] H. Prihatna, Menjadi Webmaster Profesional, Jakarta: PT. Elex Media Komputindo, 2005 